\title{
Corrective Feedback (CF) and English-Major EFL Learners' Ability in Grammatical Error Detection and Correction
}

\author{
Sahail M. Asassfeh ${ }^{1}$ \\ ${ }^{1}$ Faculty of Educational Sciences, Hashemite University, Jordan \\ Correspondence: Sahail M. Asassfeh, Faculty of Educational Sciences, Hashemite University, Zarqa, Jordan. \\ E-mail: suhailhabashneh@hotmail.com
}

Received: May 1, 2013 Accepted: June 26, 2013 Online Published: July 4, 2013

doi:10.5539/elt.v6n8p85 URL: http://dx.doi.org/10.5539/elt.v6n8p85

\begin{abstract}
Corrective feedback (CF), the implicit or explicit information learners receive indicating a gap between their current, compared to the desired, performance, has been an area of interest for EFL researchers during the last few decades. This study, conducted on 139 English-major prospective EFL teachers, assessed the impact of two CF types (implicit vs. explicit) on students' ability to detect and correct some "common" grammatical errors (definite and indefinite article, subject-verb agreement, prepositions, spelling, and logical connector use). The study used a quasi-experimental pretest, posttest with a 12-week treatment program. The results indicated a statistically significant difference in students' performance prior to and after exposure to the intervention, confirming the positive role CF has on students' performance. However, there was no significant difference attributed to the type of CF introduced. The paper sets recommendations for both practitioners and researchers and suggests a reconceptualization of the EFL learning process.
\end{abstract}

Keywords: corrective feedback, error correction, error detection, explicit feedback, implicit feedback

\section{Introduction}

In the context of teaching English as a foreign or a second language (EFL/ESL), corrective feedback (CF) constitutes a young field of research that continues to gain momentum (Russell \& Sapda, 2006) among writing instructors and applied linguistics researchers alike. CF refers to directly useable information the performer receives pointing to a gap between the current and the desired performance (Wiggins, 1993) or any implicit or explicit "feedback provided to a learner, from any source, that contains evidence of learner error of language form" (emphasis added, Russell \& Spada, 2006, p. 134). Whereas CF may address any textual dimension (e.g., content, organization, vocabulary, etc.), linguistic errors, viewed as L2 production that is not similar to the target performance (Beuningen, 2010), have been an urgent issue that attracts EFL teachers' attention (Lee, 2004). Clearly, these errors are more accessible to objective standards and their coverage does not require deep understanding of the text (Moxley, 1992).

EFL teachers and researchers' interest in CF has surfaced especially after Truscott's $(1996,1999)$ call for abandoning grammar correction in L2 writing due to the lack of compelling research-based evidence that supports this practice. Truscott's (1996) argument that CF hardly proves to help EFL writers improve their writing accuracy is based on three major assumptions: (a) the way $\mathrm{CF}$ is typically carried out hardly acknowledges the complex nature of L2 acquisition; (b) teachers' and students' willingness to participate in giving and taking CF is not always guaranteed; and (c) CF comes at the expense of time and effort that could be devoted to more productive aspects in developing students' inter-language development. However, a counter-argument has been proposed by Ferris (1999) who points to the manners in which CF, when clear, selective, and prioritized, can be effective in helping at least some language learners improve their writing or, as Polio (2012) words it, "could be effective in certain conditions" (p. 375). In response, Truscott (1999) explains that many questions are left unanswered and calls for language educators to acknowledge the general idea that $\mathrm{CF}$, which is not necessarily a deviant teaching practice, can hardly also be claimed to be a good practice (cf. Bitchener, Young, \& Cameron, 2005).

The outcome of the Ferris-Truscott debate in a nutshell calls for evidence that refutes or supports the contribution of $\mathrm{CF}$ to improving writers' product quality and the circumstances under which this evidence functions. In specific, Truscott (1999) suggests an investigation of the methods, techniques, or approaches that 
have a positive impact on students' performance. Clearly, any evidence--whether for or against CF--that neglects the context under which it functions or dysfunctions is shaded with obscurity and ambiguity.

Within the theoretical framework of CF literature, three types of CF have been identified: direct, indirect, and metalinguistic (Bitchener et al., 2005). The first type involves the teacher's provision of the correct linguistic form through the deletion of an unnecessary word, addition of a necessary one, or substitution of an incorrect word with a correct one (Ferris 2006). Although it can be beneficial for low-proficiency students; direct CF is unlikely to pay off at the long-term run as it does not require that much processing. Indirect $\mathrm{CF}$ is present when indicating to the learner that there is an error, whether precisely located in the text or not, without providing correction. Since it provides a chance for learner reflection hence more in-depth processing, indirect CF is more likely to result in long-term learning. However, it falls short behind benefiting learners when they fail to identify the exact error or provide appropriate correction (Abedi, Latifi, \& Moinzadeh, 2010). The third type, metalinguistic CF, which involves presenting an explicit comment about the error type, can be carried out in two ways: (a) providing a label or code (e.g., $s p$ for spelling, prep for preposition, etc.) or (b) providing comments about each error the learner has made. Despite the identification of these three types, the "[t]wo types of error correction that have received attention from researchers to date are 'direct' and 'indirect' CF" (Ellis, Sheen, Murakami, \& Takashima, 2008, p. $355)$.

This paper attempts to investigate the effect of two types of feedback (implicit or coded versus explicit or uncoded) on English-major EFL students' ability to detect and correct some purposefully selected common errors. These errors include the addition, substitution, or deletion of each of: (a) prepositions, (b) articles, and (c) spelling letters. Added to these are students' errors in subject-verb agreement and inappropriate logical connector use.

Targeting English-major undergraduates in this study stems from the firm belief that they are prospective teachers whose coming responsibility is to equip EFL students with a balanced use of language "between the desirability of communicative use of the FL in the classroom, on the one hand, and the felt need for a linguistic focus in language learning, on the other" (Long, 1991, p. 41). This represents a shift from meaning-only-oriented instruction towards grammar-focused interventions that simultaneously take into account the implications of Communicative Language Teaching (Richards \& Rogers, 2001), hence balancing attention to both fluency and accuracy. Those prospective teachers need to develop learners' positive affect and, no less importantly, engage in the interactive confrontational activity of error correction (Magilow, 1999).

\section{Literature Review}

Polio (2012) argues for the significance of building on SLA theory in discussing written CF. According to Polio, some approaches rarely address CF, but none suggests its uselessness. Additionally, some approaches predict that CF has a facilitative role and suggest ways for its effective use (Mackey \& Goo, 2007; Norris \& Ortega, 2000).

To contextualize CF within a SLA framework, Polio builds on six approaches that include, among others, the sociocultural theory. From a sociocultural perspective, CF goes in line with Vygotsky's (1978) sociocultural model of learning, particularly the zone of proximal development. Error identification learners with the help of a teacher constitutes one form of scaffolding since it indicates a gap between language learners' behavior on their own compared to that performed after receiving support. When this is followed by practice from learners, they become more capable of moving from regulation provided by the teacher in the form of feedback to a more self-reliant regulation and more control over the target linguistic form addressed (Sampson, 2012).

In support for this view, the findings of previous research suggest a general agreement that $\mathrm{CF}$ has a positive influence on learners' performance on posttests compared to ignoring them (Abedi, Latifi, \& Moinzadeh, 2010; Ashwell, 1990; Bitchener, Young, \& Cameron, 2005; Fathman \& Walley, 1990; Kartchava, 2012; Khatri, 2013; Russell \& Spada, 2006; Sampson, 2012). For example, Russell and Spada's (2006) meta-analysis of 34 studies indicated an overall positive effect of CF. Khatri (2013) teacher-supported CF has a positive impact on developing EFL writing skills. Ashwell's (1990) study revealed that adult L2 learners benefitted from feedback on the first and second drafts in the form of underlined or circled grammatical, lexical, or mechanical errors as well as content-oriented comments. The positive effect of feedback appeared in students' next writing which took into account three fourths of the form-oriented feedback provided, which was shown to be more beneficial than content-oriented CF. Fathman and Walley's (1990) study examined the effectiveness of form-oriented compared to content-oriented CF on the writing of intermediate ESL writers and indicated both types of CF were equally effective. Hedgcock and Lefkowitz (1994) found that EFL college students assign more value to teachers' corrections on grammatical features compared to content and style whereas ESL students prefer the second type. These studies indicate that whereas CF can be beneficial when targeting content or language, the likelihood of its 
impact is higher when language is concerned.

The introduction of linguistic CF becomes more critical given the importance EFL students and writing instructors assign to accuracy. There seems to be a general agreement that EFL learners consider writing accuracy as a major concern in their writing; thus, they seek teachers' feedback constantly (Diab, 2006; Hedgcock \& Lefkowitz, 1994; Lee, 2004, 2007; Leki, 1991). Lee (2004), for example, notes that EFL learners feel the urge to have their errors marked by their teachers. Diab (2006) also states that an overwhelming percentage of EFL students $(90 \%)$ agree or strongly agree $(55 \%)$ that they should have the fewest number of errors in their writing, and $77 \%$ agree their EFL teachers stress that their writing should incorporate the lowest number of errors. These findings support Leki's (1991) finding indicating that most L2 students in the study want their teachers to correct the errors those students make.

Given this interest in CF motivated by the persuasion of its overall impact on EFL writers' performance, recent research in L2 acquisition has developed more specific concerns that amount to investigating any possible relative variability in the impact of different CF methodologies on EFL students' writing (Beuningen, 2010). For example, Sampson (2012) carried out a small-scale study on ten Colombian-university students from Economics, Finance, and Accounting to investigate the impact of two types of feedback on subsequent writing. During four weeks, the first group received uncoded correction in the form of correct forms provided above each error whereas the second received coded annotations in the form of symbols provided for students to correct on their own. Sampson found that whereas both types of feedback contributed positively in improving students' recognition and correction of errors as well as in producing more error-free writing, coded feedback, which invited more student engagement, was more effective. Sampson recommends that feedback on persistent errors (e.g., spelling, verb tense and word choice) be a blend of both correction codes and written in-depth feedback. A further suggestion is that EFL instructors be selective in the errors they correct so as not to impede students' risk-taking in dealing with more sophisticated language forms.

With an attempt to identify an effective way to approach EFL writers' grammatical errors, Abedi, Latifi, and Moinzadeh (2010) randomly assigned 60 pre-intermediate EFL learners into two groups: the first received direct feedback (error correction) while the second received indirect feedback (error errors identified and codes provided). Comparisons were made between students' writing performance prior to, and after, receiving the two forms of feedback on five essays each participant wrote. Whereas students' performance on the pretest was comparable, their results on the posttest revealed a significant difference in favor of the group that received indirect or coded feedback.

Moreover, Bitchener, Young, and Cameron (2005) conducted a study on 53 adult migrant students to compare the impact of three types of feedback options (explicit written with a short conference with the student, explicit written only, and no feedback) on students' writing accuracy with emphasis on three grammatical aspects: prepositions, simple past tense, and definite articles. Their results revealed a significant effect for the written feedback accompanied with the short conference in using the simple past and the definite article without any impact for the three types of feedback on the combination of students' errors when these errors were clustered as one group. These results led the researchers to conclude that: "Significant variations in accuracy across the four pieces of writing support earlier SLA discoveries that L2 learners, in the process of acquiring new linguistic forms, may perform them with accuracy on one occasion but fail to do so on other similar occasions" (p. 191).

Additionally, Ahmadi, Maftoon, and Mehrdad (2012) randomly divided 60 Advanced Writing Course EFL students into three groups: a control group (no feedback provided) and two experimental ones (a direct-correction group and an uncoded-feedback group). Each participant wrote seven essays during seven weeks, and papers were all read and handed back to students according to the type of feedback they were assigned to receive. One-way ANOVA results indicated a significant role for CF in improving the writing of the experimental groups. A significant between-group difference was found in favor of the uncoded-feedback group. The researchers concluded that uncoded CF, which assigns a more active role for the EFL learner, is more beneficial than no or direct feedback.

The increasing awareness of the significance of CF has led to a shift in the predominant interest in EFL/ESL writing research, which was focused on how CF can help students become more able and self-employed writers, towards understanding the extent to which CF can foster learners' interlanguage development (Bitchener et al., 2005). Recent investigations, accordingly, tend to assess the impact of CF through comparisons prior to, and after, students' exposure to CF approaches (Bitchener et al., 2005). For example, Ellis et al. (2008) used three (pre, intermediate, and post) tests to investigate Japanese university students' gains in the accuracy of using the definite and indefinite English articles in narrative writing. One group received correction of articles only 
whereas the second received correction on articles and other textual aspects, and a third received no correction. The results showed that the two students groups who received the focused and unfocused CF outperformed the third group on the posttest, which supports the positive contribution of CF to developing students' accuracy in using articles.

An approach to $\mathrm{CF}$ as a potential source of interlanguage development which this study adopts distinguishes between teaching the language with the purpose of memorizing the grammatical patterns it has in contrast to another type of teaching that addresses the functional aspect or the implications of learning when it comes to actual practice. In this regard, Hartwell (1985) defines five types of grammar and asserts that they rarely match. The first is intrinsic knowledge of language rules and patterns which people use unconsciously; the second is the linguistic science concerned with the system of the previous grammar type; the third involves linguistic etiquette; the fourth is school grammar, the system that is oversimplified in traditional handbooks and workbooks; the fifth is stylistic grammar, which uses grammatical terms to teach. Unless aware of the mismatch between school grammar, on the one hand, and intuitive grammar, many EFL writing instructors may teach school grammar as if it were intuitive and makes all sense.

Based on the above review, some observations are noteworthy. First, most research on CF has been conducted "in an ESL context. There is a clear need for further research, especially in an EFL context" (Ellis et al., 2008, p. 355). Additionally, despite EFL instructors' tendency to provide CF, it seems clear that some questions pertinent to CF still stand in search for answers. For example, there are no conclusive results that support or refute CF usefulness. It is not yet clear also which form of feedback is more effective (direct or indirect), nor is there a clear-cut answer as to whether EFL instructors should focus their CF on specific errors (selective) or address all errors regardless of type. One more observation on the extant research is that it is not without caveats. For example, there was little control for the number of participants as well as for the period of time over which feedback provision interventions last. In Sampson's (2012) recent study, for instance, the two student groups comprised only ten students and their exposure to feedback lasted for only four weeks. Since CF may not be immediately effective but provides the learners with the opportunity to reflect on their errors and reshape their interlanguage through attempts to self-repair (Swain, 1998), the intervention period should be relatively long. This study, therefore, attempts to add to the CF literature through answering the following two research questions:

1. Is there any significant impact $(\alpha=.05)$ for EFL students' exposure to the two types of feedback (error identification and error identification and correction) on their ability to detect and correct (grammatical) errors?

2. Is there any significant difference $(\alpha=.05)$ between the impact of any of the two types of feedback (error identification only vs. error identification and correction) on EFL students' ability to detect and correct (grammatical) errors?

\section{Method}

\subsection{Research Design}

The current study used a quasi-experimental design.

\subsection{Participants}

One hundred and thirty nine students participated in this study. They were mainly second-year English-major undergraduates enrolled in two sections of a Paragraph Writing Course. The majority of the participants had been studying English for almost 13 years, and could be classified as possessing an intermediate level of proficiency. Since there were two sections of the same course offered during the semester when the study was carried out, one group was randomly assigned to receive error identification only (EIG) and the second group had their paragraphs returned to them with the errors not only underlined but also corrected, an error identification and correction group (EICG).

\subsection{Data Collection Tool}

The instrument used in this study was a grammatical error detection and error correction test (Asassfeh et al., in press). The test, a four-paragraph passage with a total number of 273 words, included 33 carefully considered instances of error occurrences with three instances representing each of eleven error types (article substitution, article addition, article omission, spelling substitution, spelling addition, spelling omission, preposition substitution, preposition addition, preposition omission, lack of subject-verb agreement, and inappropriate logical connector use). The test validity was established through presenting it to five university professors with expertise in teaching English writing at the university level and reliability was checked through administering it to a comparable group of students not taking the course during the semester when the study was carried out and 
analyzed using split-half reliability $(\mathrm{r}=.84)$. Since the test had a total of 33 errors, a student's maximum score was 33 for error identification and 33 for appropriate correction of all errors. The maximum score on the whole test, therefore, was 66 and the lowest was zero.

\subsection{Procedure}

During the second week of the first semester of the academic year 2012-2013, the study participants from two sections sat a pretest designed for the purpose of assessing their ability to detect and correct some specific grammatical errors widely reported in the literature as "common" in EFL students' writing. Students' answers were checked and fed into SPSS 20 for further comparison with their performance on the posttest.

Following the pretest, the researcher taught the two sections for the same period of time; both sections were asked to write a paragraph on an assigned topic for every week over 12 weeks. This time span was considered to provide students with a good opportunity to reflect on their writing performance, or to give a chance for the intake to be stored in students' short-term and long-term memory so that it can take the form of output (Skehan, 1998), on the one hand, and to eliminate the effect of transfer based on students' exposure to the pretest when performing on the posttest. After collecting each written text, the researcher provided two different forms of feedback written on students' own written paragraphs. One group had their assignments returned to them with direct written corrective feedback in the form of underlined errors together with the code for each error type (e.g., spelling deletion, logical connector misuse, lack of subject-verb agreement, etc.) without correction so that students correct their errors on their own, an error identification group (EIG). The second group had their paragraphs returned to them with the errors not only underlined but also corrected, an error identification and correction group (EICG). It should be noted that for both groups the students were provided with feedback on other textual aspects (e.g., content and mechanical errors) so that students' attention would not be heightened to the target errors in specific (cf. Ellis et al., 2008). Following the 12-week intervention, students from the two sections were exposed to the same test they had earlier as a posttest.

\subsection{Data Analysis Procedures}

Students' answers on the posttest, in addition to those on the pretest, were checked and then fed into and analyzed using SPSS 20. Computation was made for students' responses on each test in terms of the overall score as well as on specific error types. Descriptive (mean and standard deviation) and inferential ( $t$ test) statistics were used to answer the research questions.

\section{Results}

To answer the first question, the first statistical analysis procedure aimed at ensuring equivalence in the performance of the two student groups (EIG and EICG) prior to their exposure to the two types of feedback. The results (Table 1) indicated that pertinent to error identification, the mean score for the EIG was 9.76, $S D=5.61$ while the mean score for the EICG was $10.63, S D=5.27$. On the correction part of the test, the mean score for the EIG was 7.11, $S D=4.75$ compared to a mean score of $7.87, S D=5.08$ for the EICG.

Table 1. Descriptive statistics for the EIG and EICG scores on the pretest

\begin{tabular}{lllll}
\hline & Group & Mean & SD & Std. Error Mean \\
\hline Error Identification & EIG & 9.76 & 5.61 & .68 \\
& EICG & 10.63 & 5.27 & .63 \\
\hline Error Correction & EIG & 7.11 & 4.75 & .59 \\
& EICG & 7.87 & 5.08 & .61 \\
\hline
\end{tabular}

The mean differences between the two student groups were tested for significance using independent sample $t$-test. The results indicated that there was a significant difference neither in the performance of the two groups in error detection, $t(135)=-1.11, p=.27$ nor in the performance on error correction, $t(135)=-.89, p=.36$. These results support equivalence between the two groups in terms of their abilities in both error detection as well as error correction prior to exposure to the two types of feedback.

A comparison between students' mean scores on the pretest and the posttest is helpful for gaining an insight into the impact of students' exposure to the two types of feedback on their performance. As can be seen in Table 2, 
the mean response for the total number of participants on the pretest for detection was $10.20, S D=5.43$ compared to a mean of $19.91, S D=5.97$ on the posttest. On error correction as well, students' mean score increased from 7.50, $S D=4.90$ to $12.84, S D=6.12$ on the posttest. Thus, a comparison between students' mean correct responses on the pretest and the posttest suggests that students' ability in both error detection and error correction improved after their exposure to the two types of intervention: participants' results on detection changed almost double, with a relatively lower rate of increase in error correction.

Table 2. Descriptive statistics for the scores of all students on the pre (and post) tests

\begin{tabular}{lllllll}
\hline & \multicolumn{1}{c}{ Pretest } & \multicolumn{3}{c}{ Posttest } \\
& Total & $\mathrm{M}$ & $\mathrm{SD}$ & Total & $\mathrm{M}$ & $\mathrm{SD}$ \\
\hline Detection & 1408 & 10.20 & 5.43 & 2768 & 19.91 & 5.97 \\
Correction & 998 & 7.50 & 4.92 & 1785 & 12.84 & 6.12 \\
\hline
\end{tabular}

The mean differences between students' performance on the pretest and the posttest (Table 3) were statistically significant in both identification and correction in favor of students' performance on the posttest in both error identification and error correction. Therefore, it can be safely stated that EFL students' exposure to the two types of feedback had a significant, positive impact on their performance on the posttest at the level of both: error detection and error correction.

Table 3. T-test results comparing EFL students' performance on the pre (and post) test

\begin{tabular}{|c|c|c|c|c|c|c|c|c|}
\hline & \multicolumn{5}{|c|}{ Paired Differences } & \multirow[t]{3}{*}{$\mathrm{t}$} & \multirow[t]{3}{*}{ df } & \multirow{3}{*}{$\begin{array}{l}\text { Sig. } \\
\text { (2-tailed) }\end{array}$} \\
\hline & \multirow[t]{2}{*}{ Mean } & \multirow[t]{2}{*}{ SD } & \multirow[t]{2}{*}{ SE Mean } & \multicolumn{2}{|c|}{ 95\% Conf. Interv. Diff. } & & & \\
\hline & & & & Lower & Upper & & & \\
\hline $\begin{array}{l}\text { Identification (Pretest } \\
\text { and Posttest) }\end{array}$ & -9.63 & 5.65 & .48 & -10.58 & -8.67 & -19.96 & 136 & .000 \\
\hline $\begin{array}{ll}\text { Correction } & \text { (Pretest } \\
\text { Posttest) } & \end{array}$ & $\mathrm{d}_{-5.64}$ & 4.63 & .40 & -6.43 & -4.85 & -14.05 & 132 & .000 \\
\hline
\end{tabular}

The second research question addressed the impact of the two types of feedback (error identification vs. error identification and correction) on students' ability to detect and correct errors. At the level of individual groups (Table 4), the mean score on identification increased from 9.76, $S D=5.61$ to 20.74, $S D=6.06$ for the EIG and from10.63, $S D=5.27$ to $19.10, S D=5.80$ for the EICG. This increase was accompanied by an increase in students' performance on the correction part of the test; the mean score for the EIG, which was 7.11, SD=4.75 on the pretest, reached 12.28, $S D=6.06$ on the posttest. Likewise, the mean score of the EICG increased from 7.87, $S D=5.08$ to $13.40, S D=6.17$.

Table 4. Descriptive statistics for the EIG and EICG scores on the pretest and posttests

\begin{tabular}{llll}
\hline & Group & Mean & SD \\
\hline \multirow{2}{*}{ Pretest identification } & EIG & 9.76 & 5.61 \\
& EICG & 10.63 & 5.27 \\
\hline \multirow{2}{*}{ Pretest correction } & EIG & 7.11 & 4.75 \\
& EICG & 7.87 & 5.08 \\
\hline \multirow{2}{*}{ Posttest identification } & EIG & 20.74 & 6.06 \\
& EICG & 19.10 & 5.80 \\
\hline \multirow{2}{*}{ Posttest correction } & EIG & 12.28 & 6.06 \\
& EICG & 13.40 & 6.17 \\
\hline
\end{tabular}


The above differences in students' scores were examined for significance using independent-sample $t$-test. The results revealed that the mean difference between the mean scores of the EIG and the EICG was significant neither pertinent to error identification nor pertinent to error correction. These results suggest that the impact of the two approaches of feedback introduction was comparable. Given these results, the researchers examined whether there were statistically significant differences between the performance of the EIG and the EICG at the level of individual error types. The results indicated no significant difference at the level of any of the error types covered in this study. This result indicates that students' benefit from CF was not limited to a specific error type but not another.

\section{Discussion}

This study aimed to assess the impact of providing EFL writers with two types of CF (implicit versus explicit) on their ability to identify and correct linguistic, mainly grammatical, errors. The results indicate that students' exposure to CF, whether in the form of errors identification only or a combination of both identification and correction, had a significant, positive impact on their ability in both identification and correction. Nonetheless, despite a relative mean difference in the performance of the two student groups on the posttest, the results fail to support a statistically significant difference in the impact of providing a specific type of CF (implicit or explicit).

Despite the general agreement that $\mathrm{CF}$ can be beneficial for EFL writers, some scholars continue to argue against its fruitfulness. The findings of this study support the beneficial role CF can have in eliminating EFL writers' errors; learners become better able to identify and correct such errors. One possible reason behind the effectiveness of $\mathrm{CF}$ in the current study is its informative, rather than summative, nature. Students' constant, active interaction with the texts they wrote in both groups after each time they submitted an assignment might stand behind the positive contribution of CF to their performance on the posttest. It is worth mention that Lee (2007), who used data from multiple sources from 26 secondary teachers' written CF on 174 student texts, found that EFL teachers' feedback was mainly summative. The summative nature of $\mathrm{CF}$, accordingly, might be one of the reasons that minimize the fruitfulness of CF. Clearly, CF remains of little use, if any, unless seen and acted upon by learners.

Based on the findings of this study, two insights in agreement with Beuningen (2010) should be noted. First, the findings indicate that whereas students received $\mathrm{CF}$ on more than one textual aspect in addition to the target errors, this was not a hindrance against CF benefits in improving performance on the target errors. EFL students are likely to have attentional resources that are sufficient enough to enable them to attend simultaneously to a wide array of error types in the same text due to the off-line nature of writing that allows students to focus on several aspects of the text without being overloaded (Sheen, 2010). Secondly, despite the variability in the type of errors presented to the participants on the pretest and the posttest, the students benefitted from their exposure to $\mathrm{CF}$ when dealing with errors irrespective of the error type. This finding, which supports the correctability of different error types, contradicts Truscott's (2007) hypothesis that grammatical errors are less likely to benefit from CF. However, it supports to Nagata and Nakatani's (2010) finding that "Grammatical error detection has greatly improved in detection performance as well as in the types of the errors it is able to detect, including errors in articles, number, prepositions, and agreement" (p. 894). It also goes in congruence with Abedi et al.'s (2010) recommendation that error detection be used as a supporting strategy to implicit teaching of grammatical forms so that EFL writers can reach the highest level of writing improvement. The effectiveness of this strategy is strongly related to the value EFL students assign to comments that address grammatical writing features compared to ESL students who assign more value to content-related CF (Hedgcock \& Lefkowitz, 1994).

Moreover, the findings of the current study revealed that the form CF takes (direct or indirect) does not have a tangible impact on students' writing improvement, a finding that strongly relates to the ongoing debate among EFL writing investigators regarding the effectiveness of explicit vs. implicit CF. Beuningen (2010), for example, notes that explicit correction is more beneficial for learners than implicit CF especially when targeting "errors within the grammatical domain" (p.19). This effectiveness is attributed to the significance of providing learners with the explicit information required for cognitive learning processes (e.g., noticing and hypothesis testing). This view coincides with Ellis's (2010) observation that studies investigating the impact of implicit and explicit instruction of language, though inconclusive, indicate a superior position to explicit instruction that contributes to developing the learner's explicit knowledge, which is an essential component of language proficiency that fosters the development of implicit knowledge.

On the other hand, some empirical research findings suggest a different scenario in support for implicit feedback. To mention two recent studies, Abedi et al. (2010) found that their student group that received errors detected with the codes performed better than the group that received CF in the form of corrected errors. Moreover, 
Ahmadi et al. (2012) found a significant difference in the performance of the uncoded CF group compared the that of the direct CF group and the group that did not receive CF. The superiority of implicit CF was attributed to students' effort to locate and provide codes for errors, leading to more reflection, encouragement, and independency.

However, a closer look at these recent studies indicates that Ahmadi et al.'s (2012) study had 60 students with the treatment lasting for only 7 weeks. Abedi et al.'s (2010) study also had the same number of students and the treatment lasted for five weeks only. It is the researcher's belief in the current study that the number of the participants and the relatively short period of time might have had a role in shaping those results. Compared to these studies, the current study had a higher number of participants who were treated in a normal classroom setting for a longer treatment period of 12 weeks. The number of participants and the duration of the treatment are two variables future research should seriously consider, especially when dealing with grammatical errors. These observations lend support to Gue'nette's (2007) conclusion that finding "can be attributed to the research design and methodology, as well as to the presence of external variables that were beyond the control and vigilance of the researchers" (p. 40).

Finally, given the findings of this study that addresses the impact of implicit vs. explicit CF, it is worth noting that the two CF forms, though valuable on their own, are insightful for educators to dig deeper at the level of the theoretical underpinnings of each. That is, the explicitness or implicitness of CF is but a manifestation of what goes on in the learner's mind when processing the feedback provided. This should invite linguists and psycholinguists to revise the concepts prevalent in EFL/ESL to arrive at a clearer conceptualization of the variables at stake in EFL/ESL research in general and writing research in particular.

No less than two decades ago, Schmidt (1990) noted that "the time may be right for serious reconsideration of the phenomenon of consciousness and the role it may play in language learning" (p. 131). Schmidt opened the door for a debate that touches the very crucial terms that have governed researchers' thought at the very heart of which "consciousness" stands. To begin with, Krashen's learning vs. acquisition dichotomy in viewing an individual's experience with language seems to have resulted in some ambiguity in EFL research; the "foreignness" of the setting has typically been viewed in the literature as a "fixed" variable the implications of which can hardly be delimited. This distinction is in fact deeply rooted in relation to consciousness. That is, once the learning environment provides the learner with Krashen's comprehensible input, the EFL vs. ESL becomes less meaningful. The difference can be of less value if/when currently viewed EFL settings provide the learner with a sufficient, adequate, comprehensible input. So is the case with the distinction between "native" and "non-native" which is strongly tied to the distinction between competence and performance. The intuitive knowledge possessed by the native speaker seems not to be "inherent" but is constructed in fact based on actual interaction with and through an individual's L1.

With these considerations in mind, one can imagine a continuum that ranges between acquisition (the natural processing of language rules with a less heightened level of consciousness), at one end, and learning (exposure to the language in formal settings) at the other. "Acuairning" (a blend of "acquisition" and "learning") can be introduced as a term that encompasses the process of exposure to and self-expression through language regardless of the geographical setting where the language user resides. With this understanding, "acuairning" is introduced to help us, especially in so-called EFL settings, to conceptualize the learner's experience as one that depends on the type, richness, intensity, naturalness, and meaningfulness of input. It should also help us minimize the exaggerated role currently perceived for the geographical learning setting. That is, the "foreignness" of the language setting is not a fixed variable about which there is only little we can do.

Language educators' intellectual, perceptual handling of their instructional tasks on an "acquairning" continuum is likely to provide them with the hope to see the possibility of moving themselves and their students from the hyper-heightened consciousness associated with learning towards a less-heightened level of consciousness when introducing language. This view, it should be noted, coincides with the heart of communicative language teaching (CLT) principles. It is more likely that when teachers become fully aware of this conceptualization that their methodology would intersect with the principles of CLT falling on a continuum parallel to that associated with that of (extremely high to extremely low level of) consciousness. It is then also that the difference between implicit or explicit $\mathrm{CF}$ becomes less significant when the learner processes the feedback received regardless of the form it takes.

\section{Conclusion}

This study assessed the impact of using implicit and explicit corrective feedback (CF) on prospective teachers of English. The results support the significant role CF plays in improving students' error detection and error 
correction ability, supporting the idea that unless they are provided with the appropriate CF, EFL students--especially those whose exposure to English is limited to the classroom context--are likely to keep repeating the same errors. Both types of CF had almost the same impact on students' ability to detect and correct different grammatical error types suggesting that the contribution of the two approaches to introducing CF is relatively the same regardless of the error type CF addresses. Since this paper targets the type of errors EFL students seek CF about most, future research may address the effectiveness of the CF EFL students receive on other textual aspects such as content and writing style. The paper concludes by suggesting looking at language acquisition and learning as two points that fall on a continuum. One possible limitation in the current study lies in the lack of control to whether the participants, especially since those who had their errors identified but not corrected, have received any external help from peers, parents, friends, or tutors outside the classroom.

\section{Acknowledgment}

Many thanks are due to the students who participated in this study.

\section{References}

Abedi, R., Latifi, M., \& Moinzadeh, A. (2010). The effect of error correction vs. error detection on Iranian pre-intermediate EFL learners' writing achievement. English Language Teaching, 3(4), 168-174.

Ahmadi, D., Maftoon, P., \& Mehrdad, A. G. (2012). Investigating the effects of two types of feedback on EFL students' writing. Procedia- Social and Behavioral Sciences, 46, 2590-2595. http://dx.doi.org/10.1016/j.sbspro.2012.05.529

Asassfeh, S. M., Al-Shaboul, Y., Al Shboul, S., \& Omari, H. (in press). EFL English-major undergraduates' ability in error detection and error correction in academic writing. European Journal of Social Sciences.

Ashwell, T. (2000). Patterns of teacher response to student writing in a multiple-draft composition classroom: Is content feedback followed by form feedback the best method? Journal of Second Language Writing, 9(3), 227-258.

Beuningen, C. V. (2010). Corrective feedback in L2 writing: Theoretical perspectives, empirical insights, and future directions. International Journal of English Studies, 10(2), 1-27.

Bitchener, J., Young, S., \& Cameron, D. (2005). The effect of different types of corrective feedback on ESL student writing. Journal of Second Language Writing, 14, 191-205. http://dx.doi.org/10.1016/j.jslw.2005.08.001

Diab, R. (2006). Error correction and feedback in the EFL writing classroom: Comparing instructor and student preferences. English Teaching Forum, 3, 12-14.

Ellis, R. (2010). Does explicit grammar instruction work? National Institute for Japanese Language and Linguistics, 2, 3-22.

Ellis, R., Sheen, Y., Murakami, M., \& Takashima, H. (2008). The effects of focused and unfocused written corrective feedback in an English as a foreign language context. System, 36, 353-371. http://dx.doi.org/10.1016/j.system.2008.02.001

Fathman, A., \& Whalley, E. (1990). Teacher response to student writing: Focus on form versus content. In B. Kroll (Ed.), Second Language Writing: Research Insights for the Classroom (pp. 178-190). Cambridge: Cambridge University Press.

Ferris, D. (2006). Does error feedback help student writers? New evidence on the short-and long-term effects of written error correction. In K. Hyland, \& F. Hyland (Eds.), Feedback in second language writing: Contexts and issues (pp. 81-104). New York: Cambridge University Press.

Gue'nette, D. (2007). Is feedback pedagogically correct? Research design issues in studies of feedback on writing. Journal of Second Language Writing, 16, 40-53.

Hartwell, P. (1985). Grammar, grammars, and the teaching of grammar. College English, 47, 105-127. http://dx.doi.org/10.2307/376562

Hedgcock, J., \& Lefkowitz, N. (1994). Feedback on feedback: Assessing learner receptivity to teacher response in L2 composing. Journal of Second Language Writing, 3, 141-163.

Kartchava, E. (2012). Noticeability of corrective feedback, L2 development and learner beliefs. Unpublished PhD Dissertation. Universite de Montreal.

Khatri, R. Feedback, student collaboration, and teacher support in English as a foreign language writing. International Journal of Scientific Research, 2(2), 70-75. 
Lee, I. (2004). Error correction in L2 secondary writing classrooms: The case of Hong Kong. Journal of Second Language Writing, 13, 285-312.

Lee, I. (2007). Feedback in Hong Kong secondary writing classrooms: Assessment for learning or assessment of learning? Assessing Writing, 12, 180-198.

Leki, I. (1991). The preference of ESL students for error correction in college-level writing classes. Foreign Language Annals, 24, 203-218. http://dx.doi.org/10.1111/j.1944-9720.1991.tb00464.x

Long, M. (1991). Focus on form: A design feature in language teaching methodology. In K. Debot, R. Ginsberg, \& C. Kramsch (Eds.), Foreign language research in cross-cultural perspective (pp. 39-52). Amsterdam: Benjamins.

Mackey, A., \& Goo, J. M. (2007). Interaction research in SLA: A meta-analysis and research synthesis. In A. Mackey (Ed.), Input, interaction and corrective feedback in L2 learning (pp. 379-452). Oxford: Oxford University Press.

Norris, J. M., \& Ortega, L. (2000). Effectiveness of L2 instruction: A research synthesis and quantitative meta-analysis. Language Learning, 50, 417-528.

Magilow. (1999). Error correction and classroom affect. Teaching German, 32(2), 125-129.

Moxley, J. M. (1992). Teachers' goals and methods of responding to students' writing. Composition Studies: Freshman English News, 20(1), 17- 33.

Nagata, R., \& Nakatani, K. (2010). Evaluating performance of grammatical error detection to maximize learning effect. Coling 2010: Poster Volume, pages 894-900, Beijing, August 2010.

Polio, C. (2012). The relevance of second language acquisition theory to the written error correction debate. Journal of Second Language Writing, 21, 375-389.

Richards, J. C., \& Rogers, T. S. (2001). Approaches and methods in language teaching. New York: Cambridge University Press. http://dx.doi.org/10.1017/CBO9780511667305

Russell, V. (2009). Corrective feedback, over a decade of research since Lyster and Ranta (1997): Where do we stand today? Electronic Journal of Foreign Language Teaching, 6(1), 21-31.

Russell, J., \& Spada, N. (2006). The effectiveness of corrective feedback for the acquisition of L2 grammar. In Norris, J. D., \& Ortega, L. (Eds.), Synthesizing research on language learning and teaching (pp. 133-164). Philadelphia: John Benjamins.

Sampson, A. (2012). Coded and uncoded error feedback: Effects on error frequencies in adult Colombian EFL learners' writing. System, 40, 494-504.

Schmidt, R. (1990). The role of consciousness in second language learning. Applied Linguistics, 11, 129-158. http://dx.doi.org/10.1093/applin/11.2.129

Sheen, Y. (2010). The role of oral and written corrective feedback in SLA. Studies in Second Language Acquisition, 32(2), 169-179. http://dx.doi.org/10.1017/S0272263109990489

Skehan, P. (1998). A cognitive approach to language learning. Oxford University Press, Oxford.

Truscott, J. (1996). The case against grammar correction in L2 writing classes. Language Learning, 46(2), 327-369.

Truscott, J. (1999). The case for "The case against grammar correction in L2 writing classes": A response to Ferris. Journal of Second Language Writing, 8(2), 111-122.

Truscott, J. (2007). The effect of error correction on learners' ability to write accurately. Journal of Second Language Writing, 16(4), 255-272. http://dx.doi.org/10.1016/j.jslw.2007.06.003

Vygotsky, L. S. (1978). Mind in society: The development of higher psychological processes. Harvard University Press, Cambridge, MA.

Wiggins, G. (1993). Assessing student performance. San Francisco: Jossey-Bass.

\section{Copyrights}

Copyright for this article is retained by the author(s), with first publication rights granted to the journal.

This is an open-access article distributed under the terms and conditions of the Creative Commons Attribution license (http://creativecommons.org/licenses/by/3.0/). 